\title{
SOME MIXED WEAK TYPE INEQUALITIES
}

\section{MARÍA LORENTE AND FRANCISCO J. MARTÍN-REYES}

Abstract. We study mixed weak type $(1,1)$ weighted inequalities for the Hardy averaging operator, $T_{c} f(x)=\chi_{(c, \infty)}(x) \frac{1}{x-c} \int_{c}^{x} f(y) d y$. This type of inequalities have the form

$$
\int_{\left\{x \in \mathbb{R}:\left|T_{c} f(x)\right|>v(x)\right\}} u v \leqslant C \int_{\mathbb{R}}|f| u,
$$

where $C$ is independent of $f$ and $c$. We improve the results in [Q. J. Math. 60 (2009), no. 1, 63-73] by giving a wider class of pairs of weights for which the inequality holds. In particular, and as a corollary, we prove that the inequality holds for $u \in A_{1}^{-}$and $v \in A_{\infty}^{+}$.

Mathematics subject classification (2020): Primary 42B25; Secondary 26D15.

Keywords and phrases: One-sided operators, Hardy type operators, mixed weighted inequalities.

\section{REFERENCES}

[1] Kenneth F. Andersen and Benjamin Muckenhoupt, Weighted weak type Hardy inequalities with applications to Hilbert transforms and maximal functions, Studia Math. 72 (1982), no. 1, 9-26, doi:10.4064/sm-72-1-9-26, MR665888.

[2] FABIO BERRA, Mixed weak estimates of Sawyer type for generalized maximal operators, Proc. Amer. Math. Soc. 147 (2019), no. 10, 4259-4273, doi:10.1090/proc/14495.

[3] Fabio Berra, Marilina Carena and Gladis Pradolini, Mixed weak estimates of Sawyer type for commutators of generalized singular integrals and related operators, Michigan Math. J. 68 (2019), no. 3, 527-564, doi:10.1307/mmj/1559894545.

[4] Fabio Berra, Marilina Carena And Gladis Pradolini, Mixed weak estimates of Sawyer type for fractional integrals and some related operators, J. Math. Anal. Appl. 479 (2019), no. 2, 14901505, doi:10.1016/j.jmaa.2019.07.008.

[5] D. Cruz-Uribe, J. M. Martell, C. PÉrez, Weighted weak-type inequalities and a conjecture of Sawyer, Int. Math. Res. Not. 30 (2005), 1849-1871, doi:10.1155/IMRN.2005.1849, 2172941.

[6] David E. Edmunds, Vakhtang Kokilashvili And Alexander MeskHi, Bounded and compact integral operators, Mathematics and its Applications, vol. 543, Kluwer Academic Publishers, Dordrecht, 2002.

[7] Elida V. Ferreyra, Weighted Lorentz norm inequalities for integral operators, Studia Math. 96 (1990), no. 2, 125-134, doi:10.4064/sm-96-2-125-134, 1052629.

[8] Kangwei Li, Sheldy Ombrosi and Carlos Pérez, Proof of an extension of E. Sawyer's conjecture about weighted mixed weak-type estimates, Math. Ann. 374 (2019), no. 1-2, 907-929, doi:10.1007/s00208-018-1762-0, 3961329.

[9] F. J. MARTÍN-REYES, New proofs of weighted inequalities for the one-sided Hardy-Littlewood maximal functions, Proc. Amer. Math. Soc. 117 (1993), no. 3, 691-698, doi:10.2307/2159130, 1111435.

[10] Francisco J. Martín-Reyes And Sheldy J. Ombrosi, Mixed weak type inequalities for onesided operators, Q. J. Math. 60 (2009), no. 1, 63-73, doi:10.1093/qmath/han009.

[11] F. J. Martín-Reyes, P. Ortega Salvador and M. D. Sarrión Gavilán, Boundedness of operators of Hardy type in $\Lambda^{p, q}$ spaces and weighted mixed inequalities for singular integral operators, Proc. Roy. Soc. Edinburgh Sect. A 127 (1997), no. 1, 157-170, doi:10.1017/S0308210500023556, MR1433089. 
[12] F. J. Martín-Reyes, P. Ortega Salvador And A. DE LA Torre, Weighted inequalities for one-sided maximal functions, Trans. Amer. Math. Soc. 319 (1990), no. 2, 517-534, MR0986694 (90j:42047).

[13] Benjamin Muckenhoupt, Weighted norm inequalities for the Hardy maximal function, Trans. Amer. Math. Soc. 165 (1972), 207-226, doi:10.2307/1995882, MR293384.

[14] Benjamin Muckenhoupt And Richard L. Wheeden, Some weighted weak-type inequalities for the Hardy-Littlewood maximal function and the Hilbert transform, Indiana Univ. Math. J. 26 (1977), no. 5, 801-816, doi:10.1512/iumj.1977.26.26065, MR447956,

[15] C. PÉREZ AND E. Roure-PERDICES, Sawyer-type inequalities for Lorentz spaces, preprint.

[16] E. SAWYER, A weighted weak type inequality for the maximal function, Proc. Amer. Math. Soc. 93 (1985), no. 4, 610-614, doi:10.2307/2045530, MR776188.

[17] E. SAWYER, Weighted inequalities for the one-sided Hardy-Littlewood maximal functions, Trans. Amer. Math. Soc. 297 (1986), no. 1, 53-61, doi:10.2307/2000455, MR849466. 